of cardiac and respiratory stimulants, artificial respiration, friction of the extremities, and cold affusions to the spine, with the patient in a warm bath, or the use of the alternate hot and cold douche to the spine, offer the best results. Various drugs have been suggested as additions to water in washing out the stomach: hydrogen peroxide; potassium permanganate; ferric and ferrous salts in combination; carbonate of potash in solution or in combination with sulphate of iron and ether. Of these probably the best is the permanganate of potassium, the use of which is recommended by Kossa $^{18}$ and other writers. Witherstine ${ }^{17}$ calls attention to the article of Heim, ${ }^{18}$ in which the author states that "morphine seems to be the antidote to cyanide of potassium, and vice versa."

\title{
REFERENCES.
}

1. Witthaus. Toxicology, 1896, voi. iv. p. 604.

2. Souwers. Philadelphia Medical Times, 1877-1878, vol. viil. p. $\$ 45$.

3. British and Foreign Med.-Chir. Review, Jniy, 1876, p. 281.

2. Bennett. Medicai Record, 1894, vol. xlv. p. 742.

5. Casper-Liman. Handbuch d. ger. Med., 8te Aufl, Bd. ii. p. 496.

6. Valcourt. Union medicale, 1875, 3 s., tome $\times x$. p. 626 .

7. Haskins. Boston Medical and Surgical Journal, 1870, vol. $1 \times \times \times 11$. p. 21.

8. Higgins. Medieal Record, 1891, voi. xl. p. 687.

9. Wiglesworth. British Medical Journal, 1897, vol. i. p. 1039.

-10. Stevenson. Lancet, 1871, vol. 1. p. 806.

11. Quintin, Berl. klin. Wochenschrift, 1885, Bd. xxil. p. 120.

12. Brockett. Lancet, 1886, vol. il. p. 1174.

18. Gillibrand. Lancet, 1876, vol. il. p. 223.

14. Dobson. British Medical Journal, 1896, vol. 1. p. 17.

15. Med.-Chir. Rundschan, 1867, 195, ex Friedreich's Bl. f. ger. Med., 1868, Bd. xix. p. 452.

16. Kossa. Therap. Monatsh., 1892, Bd. vi. p. 549.

17. Witherstine. Sajous' Cyclopedis of Practical Medicine, 1902, vol. v. p. 337.

18. Helm. Münch. med. Woch., 1896, No. 37.

\section{EVENTRATION OF THE DIAPHRAGM, WITH A REPORT OF A CASE.}

\author{
By Joseph SAILER, M.D., \\ PEYBICAAN TO THE PEILADELPETA HOSPTTAX, \\ AND \\ ROBERT D. RhEIN, M.D., \\ LATE RESIDENT PEYGICIAN TO TYB PHTLADELPHIA HOAPITAL.
}

Eventration of the diaphragm has been known ever since J. L. Petit reported and named a case in 1790 . It may be described as an abnormally high position of the left half of the diaphragm, with dislocation upward of the abdominal viscera, particularly the stomach, on the left side; hypoplasia of the left lung, and displacement of the heart to the right. It gives rise to physical signs closely resembling those diaphragmatic hernia. Its proper 
classification has been a matter of considerable difficulty. The greater number of writers (Laacher, Thoma, Leichtenstein) include it among the forms of diaphragmatic hernia, regarding the distended diaphragm reaching high into the abdominal cavity as a part of the hernial sac, the other layers being the pleura above and the peritoneum below. Others (Reinhold) consider the chief feature the hypoplasia of the lung. A third group (Crispino) regards such cases as instances of dextrocardia, a fourth group (Doering) as primary defects of the diaphragm, and a fifth group (Cruveilhier, Glaser) as possibly acquired lesions.

The following case was observed at the Philadelphia Hospital in the service of Professor James Tyson, to whom we desire to express our thanks for permission to publish it:

H. H., white, aged twenty years, a farmer.

Family History. His father died at the age of seventy; his mother was living. She was said to be nervous and to have had "spells" until she was twenty years old. Five half-brothers and three half-sisters were all said to be nervous.

Present History. Patient had one convulsion in infancy, a second at the age of fifteen years, and since then they had occurred about once a week; otherwise he had been healthy. The convulsions appear to have been typical epileptic attacks commencing with nausea and vertigo, and followed by unconsciousness, during which the patient fell to the ground, but rarely injured himself. Sometimes he bit his tongue. After the attacks he felt exhausted, had headache, and ordinarily slept for two or three hours. When he awoke he complained of peculiar dreams. He was admitted to the ward for nervous diseases in the service of Dr. Charles W. Burr, where it was noted that he was well developed, well nourished; that the pupils were equal and reacted normally; that there were no pareses, but that the tongue showed a constant tremor. It was also noted that there was hyperresonance over the whole left side of the chest; that the area of cardiac dulness was absent; that the apex beat could be felt to the right of the sternum; that the other organs were normal in position. Three days after admission he began to complain of abdominal pain; he developed fever, and had an enlarged spleen, and three days later rose-colored spots appeared upon the abdomen. He was therefore transferred to the medical ward. Upon admission the following notes were made:

"The left side appears to be larger than the right; no cardiac impulse is visible on palpation to the left of the sternum, but there is distinct impulse visible in the third, fourth, and fifth interspaces to the right of the sternum. The percussion note over the left side is tympanitic below and resonant.above the second interspace. The tympanitic note extends from the midsternal line to the midaxillary line. On the right side there is a little fulness in the upper portion of the chest, and tenderness as far down as the second rib. 
The percussion note is resonant, but not tympanitic. In the third, fourth, and fifth interspaces there is an area of dulness which is continuous with the liver dulness, extending from the midsternal to the parasternal line. The respiratory souuds are absent on the left side below the level of the fourth rib anteriorly, and below the level of the third rib laterally. Below this point a considerable amount of gurgling and bubbling can usually be heard. Above the fourth rib the respiratory sounds are vesicular, but harsh. The heart sounds are faint on the left side and loud on the right side, and the second sound is distinctly accentuated. The patient shows general cyanosis."

History in the Medical Ward. One week before admission, after exposure, the patient had a chill, acconipanied by vomiting. Since then he had been feverish and chilly, and had had several attacks of epistaxis, and cough with blood-streaked expectoration. There had been some pain in the abdomen.

April 10, 1902, the following notes were made: "The tongue is moist and tremulous; the pulse rapid, weak, and regular. There is bulging in the intercostal spaces on the left side, and a visible cardiac impulse in the third, fourth, and fifth interspaces just to the right of the sternum. Percussion resonance is normal on the left side as far as the second rib; below this there is distinct tympany extending from the midsternal to the midaxillary line. If the patient inspires deeply the upper border of the tympanitic area descends about an inch. There is a slight prominence in the right infraclavicular space which is tender. The area of cardiac dulness extends one inch to the right of the sternum, and from the lower border of the third rib to the hepatic dulness. The percussion note over the rest of the right side is clear. The breath sounds are very faint on the left side below the third rib. Over the tympanitic area bubbling, gurgling, and splashing are heard. When the patient swallows water and the stethoscope is placed over the tympanitic area the gurgling sounds are clearly transmitted to the ear. The heart sounds are faint on the left side, but loud on the right, and there is accentuation of the second sound. In the lower part of the left side anteriorly there is a to-and-fro sound resembling friction rub. When the patient is placed upon the right side the area of tympany extends as far back as the posterior axillary line. There is dulness along the left border of the sternum. Posteriorly the breath sounds can be heard indistinctly at the base of the left chest. The coin test is not obtained."

The following extracts from the notes relate most intimately to the physical condition:

April 11th. Two exploratory punctures were made, but were entirely negative. It felt as though the needle were in a hollow cavity. The course of the disease has been steadily progressive. From time to time the patient has had severe hemorrhage from 
the bowels; the diazo and Widal reactions have been positive, and the eruption is typical. The respirations are never very rapid.

14th. There seems to be a slight but appreciable movement of the area of dulness to the right of the sternum, farther to the right and slightly upward.

15th. Auscultatory percussion over the tympanitic area indicates that it is apparently continuous with the abdominal cavity. When the stethoscope is placed over this area, and the abdomen tapped, the sound is clearly transmitted, unless the tapping is made over the area of liver dulness, over the right lung, or above the third rib.

25th. The patient has had an epileptic attack. For the preceding two days he-has had dyspnoea.

After this date he continued to grow worse, extensive and uncontrollable bed-sores developed, he expectorated large quantities of rusty sputum, the respiration, increased in frequency, and the heart was apparently displaced slightly farther to the right. The area of tympany remained unchanged. Posteriorly there was a slight area of dulness extending from the angle of the scapula to the base of the lung. This area moved slightly when the patient was rolled upon the right side. Over it the breath sounds were harsher than over the tympanitic area. The pulse bccame weaker, and at 8.45 on the morning of April 30, 1902, the patient died. The blood count was made only once, when there were 4000 leukocytes. Throughout the course of the disease he had suffered from excessive thirst. Litten's phenomenon was never satisfactorily obtained, partly on account of the serious condition of the patient.

Immediately after death Dr. G. E. Pfahler took a.skiagram of the thorax and abdomen of the patient. This was not developed until after the autopsy, but would alone liave rendered the nature of the condition perfectly clear.

The diagnosis of this condition presented many difficulties, chiefly on account of our unfumiliarity with the condition. At various times we suspected pneumothorax, diaphragmatic hernia, pulmonary cavity, and high position of the diaphragm. In a subsequent study of the literature it appeared that we should also have considered subdiaphragmatic pyopneumothorax and unilateral paralysis of the phrenic nerve. In favor of pneumothorax was the movable dulness on the left side posteriorly. This, however, was always doubtful, and the condition appeared to be excluded by the absence of dyspncea, the equal expansion of the two sides during respiration, the negative coin test, the movement of the upper border of the tympanitic area during respiration, failure of the supposed fluid to increase during the course of the disease, and the absence of leukocytosis. A tympanitic note, moreover, is rather uncommon over a pneumothorax. The diagnosis of diaphragmatic hernia was concurred in by Dr. Riesman, who also saw the case. 
In favor of this was the area of tympany in the lower portion of the left chest, the dislocation of the heart to the right, the loud gurgling heard in the tympanitic area when the patient swallowed water, and the excessive thirst. Against it was the absence of dyspnoea, the equal expansion of the two sides, the area of dulness posteriorly, and particularly the distinct respiratory movement of the upper border of the tympany. Cavity in the lower portion

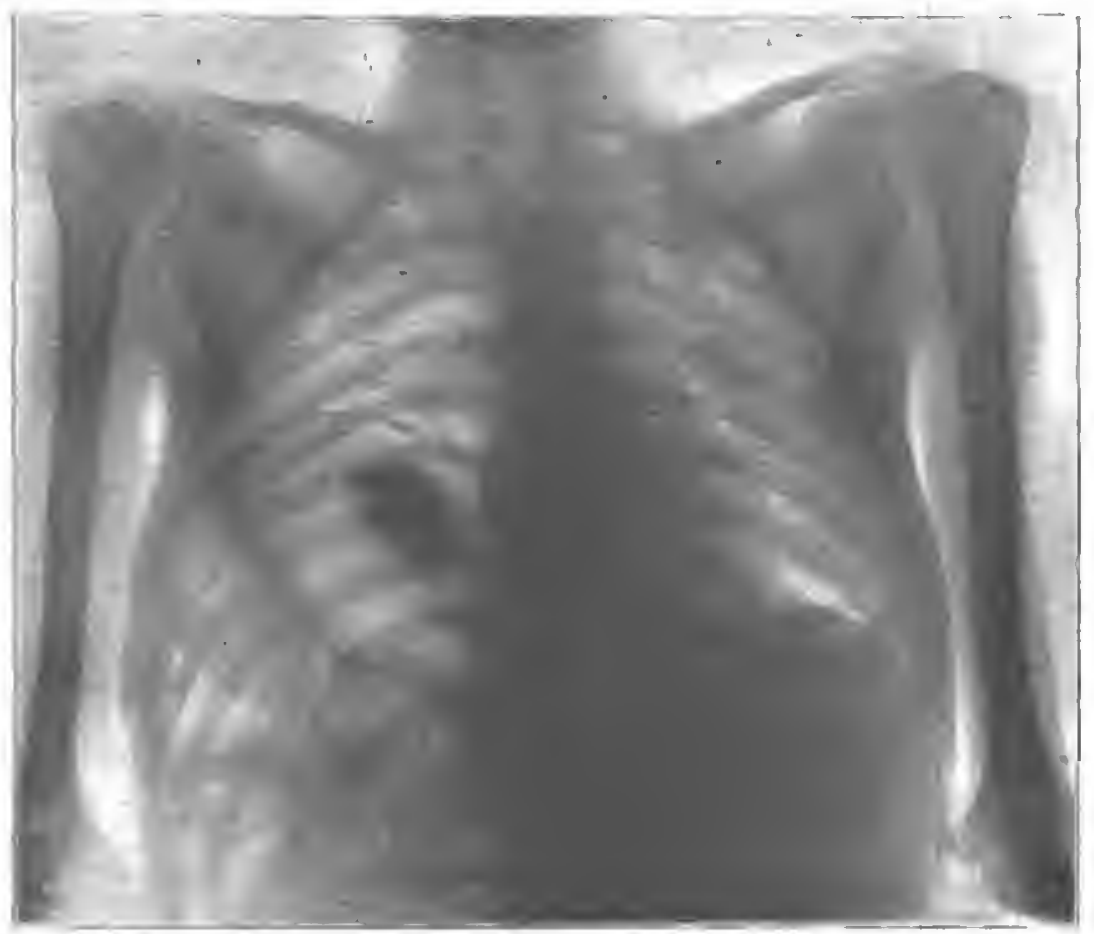

The skiagram was taken with the patient's back to the plate. It is, therefore, as if the patient were standing with his hack toward the spectator. On the right side is seen the heart, and below that the convex upper surface of the liver, indicating the position of the right half of the diaphragm. On the left side there is, next to the spinal column, a narrow band of shadow indicating the left border of the heart. Then, arising from the vertebral end of the seventh rih, arehing to the left and upward as far as the fifth rib and axillary line there is a convex shadow indicating the position of the left half of the diaphragm. The large dark mass just below this was found at the autopsy to be a huge coagulum of milk lying in the stomach. Below this the attachment of the diaphragm can be seen, represented by a broader line convex on the upper surface, and below this and to the left of the vertebral column a lighter shadow, indicating the position of the spleen. (The skiagram was taken by Dr. G. E. Pfahler.)

of the left lung was also suggested, but there was neither bronchophony nor pectoriloquy over the tympanitic area, no paroxysms of profuse expectoration, and in cavity formation dislocation of the heart, excepting toward the cavity, is exceedingly uncommon. 
High position of the diaphragm accounted satisfactorily for the dislocation of the heart, the respiratory movement of the upper border of the tympany, and for the gurgling heard over the tympanitic area, particularly if the water was swallowed during auscultation. We did not understand why there should have been a supposed movable dulness posteriorly, nor could we account for the friction sound occasionally heard in the fifth interspace near the left midaxillary line. Nor was there any obvious cause why the diaphragm and with it the abdominal viscera should have been displaced. It was therefore supposed that it might be congenital, possibly one of the forms of physical anomaly sometimes associated with epilepsy. Hypoplasia of the left lung was not suspected during the patient's life.

The autopsy was made by Dr. Prince five hours after the patient had died. The pathological diagnosis was: Congenital malformation and hypoplasia of the left lung, compensatory distention of the left half of the diaphragm, splenic tumor with septic infarction, enlargement of the liver, acute nephritis, and enteric fever. The most important parts of the notes are as follows:

There was a large bed-sore over the sacrum and one over the seventh cervical vertebra; also beginning bed-sores on each heel. Abdominal cavity: The lower edge of the stomach could be seen just beneath the costal border; its position was almost vertical. The spleen was greatly enlarged; its lower border was at the level of the border of the ribs anteriorly. The left kidney was in its normal position. The tail of the pancreas pointed vertically upward along the left side of the sternum. The diaphragm turned sharply upward just behind the xiphoid cartilage, and on the left side reached to the third intercostal space. On the right side it reached to the fifth rib. Thoracic cavity: The left pleural cavity was abnormally small, the dome of the diaphragm reaching high into the chest. The heart was displaced toward the right and extended $5 \mathrm{~cm}$. to the right of the midsternal line, and from the third to the sixth ribs. The left lung was abnormally small; the length of the outer edge was $16 \mathrm{~cm}$. and of the anterior edge $13 \mathrm{~cm}$. Its greatest width was $18 \mathrm{~cm}$. The lower lobe was imperfectly divided into three small lobes; there were some areas of atelectasis posteriorly and slight emphysema anteriorly. The right lung was apparently normal in size. The middle lobe was imperfectly separated from the upper. It was slightly emphysematous and showed a few sinall areas of atelectasis. The spleen measured $15 \times 6 \mathrm{~cm}$. The substance was firm; there was a large, softened, anæmic infarct on the greater convexity, and a second somewhat smaller infarct a short distance from this. It was placed close to the spinal column, with its long axis vertical and extending upward to the level of the sixth dorsal vertebra. Microscopically the diaphragm contained muscular fibres. 
The physical signs were satisfactorily explained by the autopsy. The left lung was less than half its normal size, and the small areas of atelectasis at the surface did not permit, in the presence of emphysema of the other portion, of the supposition that it had ever been compressed. It must, therefore, have been hypoplastic, and coincidently with this hypoplasia the diaphragm had risen to fill the left pleural cavity. The diaphragm was moderately thin, but microscopically was found to contain a fair amount of muscular tissue, which accounted satisfactorily for the respiratory movement. The area of dulness to the left of the sternum posteriorly was evidently due to the greatly enlarged spleen which was found in this situation, and it is entirely possible that in rolling the patient from side to side this large and heavy organ may have shifted enough in position to give the impression of movable dulness. It is also possible that the rubbing of the spleen against the wall of the abdomen gave rise to the friction sound. No other cause was found at the autopsy.

The condition was unquestionably congenital, for, in addition to the peculiar deformity of the left lung, it seems likely that the dislocation of the tail of the pancreas upward must have occurred during embryonal existence.

The following list of cases of this condition is as complete as we could make it. Unfortunately it was impossible to verify all of the references, and some of the cases are so incompletely reported in abstract that their nature is doubtful:

CASE I.-Jean Louis Petit mentions the case of a woman who had had attacks of asthma for some years, which were usually relieved by eating. She died of inflammation of the stomach (peritonitis?), and at the autopsy a tumor the size of a small gourd was found projecting into the left pleural cavity. It contained the stomach, colon, and great omentum. Its wall was composed of the pleura, the peritoneum, and the diaphragm. He describes it as a form of diaphragmatic hernia.

CASE II.-Lawrence reports the results of an autopsy in which the liver was found displaced in the right lumbar region; the diaphragm on the left side reached to the second rib, forming a sac which contained a greatly dilated stomach. The left lung was reduced to the size of a fist, and the left half of the diaphragm formed a thin, flaccid septum which was continuous with the muscle on the opposite side. The right half was normal. The position of the heart is not mentioned.

Laacher, in his article, mentions the two following cases:

CASE III.-Pyl describes the findings of an autopsy upon a newborn infant. On the left side the diaphragm was thin and dilated as if it were a hernial sac. This sac contained the stomach, spleen, ileum, and the curve of the colon. The heart was pushed to the right. He regards it as a hernia vera. 
CASE IV.-Meckel describes a female foetus, the left side of whose diaphragm was dilated into a sac containing the stomach, the jejunoileum, the creum, the colon, and the spleen.

CASE V.-Froriep mentions the case of a girl who died at the age of nineteen years. She often had dyspnoea and vomiting and other digestive disturbances. From the fourteenth year she had had obstinate constipation. At the autopsy the left half of the diaphragm appeared as a sac reaching upward into the pleural cavity, and containing the stomach. The heart was pushed considerably to the right. The diaphragm was abnormally thin, and in the neighborhood of the mediastinum was transformed into transparent cellular tissue. This abnormal thinness appeared to be congenital, for no other cause, such as inflammation of the diaphragm or of the diaphragmatic pleura, existed.

CASE VI.-Marsh reports the case of a man who had a severe shock followed by a sense of something giving way, and then cough, dyspnoea, and pain in the left side of the chest. At the autopsy the left half of the diaphragm arched into the left pleural cavity as high as the level of the left intercostal space. The stomach was concealed beneath the ribs. The liver lay below and in front of it. The right half of the diaphragm was normal. The left half contained a few muscular fibres; the left crus was about half the size of the other. The lungs showed the changes of acute croupous pneumonia, but were otherwise normal; their size is not mentioned.

CASE VII.-Thoma describes the findings at the autopsy of a man of seventy-five years who had died of peritonitis. The diaphragm reached to the fifth rib on the right side and to the third interspace on the left side. The left half formed a large sac containing the stomach, spleen, the left lobe of the liver, and part of the colon, all of which were displaced upward. The apex of the heart was in the median line just above the xiphoid cartilage. The upper lobe of the left lung was large and extended far to the right; the lower lobe was very small, so that the whole lung was shorter. The right lung was deeply grooved on the anterior surface to receive the heart. The spleen was moderately and the stomach greatly enlarged. Thoma naturally regards the condition as congenital, particularly as other forms of congenital hernia were present.

CASE VIII.-Crispino reports, as an instance of congenital dextrocardia, the case of a woman fifty-five years of age. There was no deformity of the chest. There was a small left inguinal hernia. The apex of the heart could be felt in the fifth interspace in the right anterior axillary line; the heart dulness commenced at a point above the fourth rib and extended from the right border of the sternum to a line between the right nipple line and the right anterior axillary line. The lungs were entirely negative. Auscultation of the heart revealed only slight arrhythmia. He expressly 
states that the spleen, stomach, liver, etc., were in their normal positions. But he then describes a radiograph which showed that the heart was greatly displaced to the right, and that the left half of the diaphragm was higher than the right, the difference being about four inches. It moved easily and synchronously with the heart. The left lung appeared to be short, but very broad.

CASE IX.-Kronig reported very briefly before the Berlin Medical Society, as an instance of dextrocardia, the case of a man, fortyeight years of age, who died of pneumonia, and in whom, before death, a diagnosis of dextrocardia had been made. At the autopsy the heart was found dislocated to the right, but not otherwise anomalous. The left lung was very broad, and the relation of the lobes was altered so that the upper lobe lay directly in front of the lower.

CASE X.-Tennant reports the case of a man of sixty years who had had syphilis and psoriasis, and died as the result of double pneumonia. There was nothing in his clinical history to indicate disease of the gastrointestinal tract, and apparently nothing unusual had been discovered in the physical signs. The condition was found during dissection. There was no obvious external deformity excepting large bilateral inguinal hernias, which were not congenital. On the right the diaphragm extended to the fourth interspace; on the left the anterior third of the diaphragm was normal, then it bent sharply upward, forming an edge from the tenth rib to the central tendon, and a pouch that extended to the second interspace. This contained a distended stomach and coils of the transverse colon, which was fifty-five inches long. The membrane forming the pouch was thin and translucent, and contained only a few muscular fibres examined macroscopically. The apex of the heart was three inches to the right and one and a half inches to the right of the median line; the base was normal. The lungs were also normal and equal in size. The left phrenic nerve did not show any obvious degeneration. Tennant believes that the condition must either have becn congenital or acquired as a result of the degeneration of the muscle of the diaphragm or the terminations of the phrenic nerve.

CASE XI.-Doering reports the case of a man of sixty years who had always performed severe manual labor. His thorax was slightly barrel-shaped but symmetrical, and there was possibly a slight diminution of the respiratory excursion on the left side posteriorly. Otherwise it was normal. Litten's phenomenon could not be satisfactorily determined. Percussion of the left side anteriorly showed slight impairment of resonance as far as the third rib; below this point there was a loud tympanitic note. Posteriorly the area of tympany commenced at the level of the fourth spine of the vertebra. On the right side percussion was entirely normal. The cardiac pulsation could be seen and felt in the fourth inter- 
space, a finger's breadth to the inner side of the right nipple line. The dulness extended from one finger's breadth to the left of the left border of the sternum as far as the right nipple line, to the level of the third rib and the liver. Auscultation showed vesicular respiration at the apex of the left lung, loud intestinal gurgling over the tympanitic area, normal vesicular respiration over the right lung, and an accentuated pulmonic second. A diagnosis was made of dislocation of the heart and retraction of the left lung. At the autopsy the diaphragm was found reaching to the sixth rib on the right side, then bending sharply upward at the suspensory ligament of the liver, and forming a large sac the apex of which reached to the upper border of the third rib. The heart was entirely dislocated to the right, but was in itself normal. There were no pleural or pericardial adhesions. The lung consisted of three lobes. The left lung was small, measuring $14 \mathrm{~cm}$. vertically, $12 \mathrm{~cm}$. in breadth, and $6 \mathrm{~cm}$. in length. The tissue was normal excepting a slight pigmented induration of parts of the middle and lower lobes. The right bronchus was larger than the left. There were no bronchiectases. The sac formed by the diaphragm contained portions of the stomach and colon and a large nuass of intestinal loops. The spleen was small and in its normal position. The microscopic examination of the diaphragm showed that it consisted of three layers, one of the pleura, another of the true diaphragm, and between them a layer of laminated connective tissue. 'The muscular fibres were greatly diminished, and in the upper third of the sac were entirely absent. The left lung was normal.

CASE XII.-In 1901 Widenmann reported as an example of diaphragmatic hernia diagnosed during life the case of a man, forty-eight years of age, who had had four attacks of pleurisy. The last attack had commenced with profuse hemorrhage from the stomach. He was transferred to the hospital, where it was found that the left thorax was slightly prominent above and slightly retracted below. The expansion was almost equal. On the left side from the second rib to the fourth rib there was a hyperresonant note, and from the fourth rib downward tympany. Posteriorly there was loud tympany from the angle of the scapula to the level of the ninth spinous process, and below this dulness which continued to the upper border of the spleen. In the tympanitic area the breath sounds were practically absent, and on this account the intestinal gurgling could clearly be heard. Hippocratic succussion could be obtained after taking food. The heart was dislocated to the right; the area of dulness changed considerably with the position. The stomach contents were normal. When the stomach was distended there was no prominence in the left hypochondriac region; the area of tympany rose one interspace higher in the left chest. In order to confirm the diagnosis the patient was studied by the aid of the Roentgen rays, and a large clear space seen in the 
lower border of the left thorax, bounded above by a line convex upwardly. On the first examination this moved with respiration, and a diagnosis of high position of the left diaphragm was made.

Later a transverse line below the clear area could be seen moving with the respiratory excursion, and a diagnosis was made of diaphragmatic hernia, the supposition being that the opening was in the posterior portion of the diaphragm, and that the left lobe of the liver had also -passed through it, accounting for the area of dulness posteriorly. Notes taken twenty-six years before in the military hospital revealed practically the same condition. A year later Glaser reported the same case. The physical signs were practically the same. Litten's phenomenon could not be observed. If the stomach were filled with water, dulness appeared in the lower portion of the tympanitic area. The patient again had hæmatemesis, and incarceration of diaphragmatic hernia was diagnosed. An operation was performed, at which high position of the diaphragm was discovered. The spleen was dislocated upward, lying to the left and back of the fundus. The patient recovered from the operation, but a year later died from carcinoma of the tongue. At the autopsy the right apex of the diaphragm was found at the lower border of the fifth rib; the left apex at the level of the third interspace. The left half of the diaphragm contained the stomach and some intestinal loops. When the stomach was inflated the apex of the diaphragm on the left side rose to the level of the second interspace. The colon, duodenum, liver, and kidneys were normal in position; the spleen was dislocated upward; the heart was to the right. The left lung consisted of two lobes, the upper covering the lower. Benda examined the diaphragm and found what was apparently a fatty degeneration of the muscular fibres. Fraenkel, in whose service the case occurred, therefore regards it as an acquired high position of the diaphragm caused by a pseudohypertrophic lipomatosis of the diaphragmatic muscle.

In view of Widenmann's discovery of the record that showed that at the age of twenty-two years practically the same condition existed, the disease must have commenced in early life. Somewhat similar cases, both as regards the physical signs and the results of Roentgen examination, have been reported by Hirsch and Strüppler. Both have been diagnosed as diaphragmatic hernias, but it is entirely possible that they may really have been cases of eventration of the diaphragm.

In addition to these cases there are several other doubtful cases in the literature: 1 by C. J. Clark, in which it is not clear whether the condition was congenital or acquired; 1 by Abercrombie, 1 by Barlow, and 1 by Fitzgerald and Ernst, The 
data are insufficient, and therefore it is not possible to include these cases.

Summarizing these 13 cases we find that 1 was a fotus; 1 a newborn infant. In 8 the age is given and ranged from nineteen to seventy-five years; in 3 it is merely stated that they were adults; 4 were females, 7 were males, and in 2 the sex was not given.

The clinical symptoms were various. In 1 there was asthma relieved by eating; another, a girl of nineteen, had suffered from vomiting and constipation; a third, a man of fifty, had had a number of attacks of hrmatemesis and symptoms of incarceration of a diaphragmatic hemia for which operation was performed. One patient had inguinal hernia, another bilateral inguinal hernia, and 1 suffered from epilepsy. In 2 cases evidences of peritonitis were found at the autopsy. One died of pneumonia, 1 of typhoid fever, and 1 of carcinoma of the tongue.

In 12 of these cases autopsies have been obtained; 1 , the case of Crispino, is still alive, but the diagnosis appears to be established by the radiogram.

In 8 of the 12 cases the diagnosis was not suspected. In 1 a diagnosis of dextrocardia had been made during life, and in 3 the diagnosis was made with a reasonable certainty during life, Doering diagnosing high position of the diaphragm with retraction of the left lung, Glaser having established the dignosis at an exploratory operation, and in our case the diagnosis of high position of the diaphragm having been made.

The condition of the lungs is mentioned in 8 cases. In 2 of these it is stated that they were normal, and in 1 particularly that they were of the same size. In 6 cases they were abnormal. Twice three lobes were present, and the lung was small, and in the remaining 4 cases the upper lobe was relatively much larger than the lower lobe, and its position in relation to it was somewhat anomalous.

The only important conclusion to be deduced from these figures is that eventration of the diaphragm does not interfere with the duration of life, nor does it necessarily produce clinical symptoms.

With this scanty material it would not be justifiable to attempt to draw any very definite conclusions were it not for the fact that all the cases exhibit a very remarkable similarity; indeed, with unessential variations, the description of the autopsy in one case might readily be used for all the others.

Regarding the nature of the condition there is some dispute. Cruveilhier intimates, but does not explicitly state, that in the case of Petit, which he studied, it may have been acquired. The evidence for this was in part the coexistence of peritonitis, but subsequent authors-with, I believe, the exception of .Glaser, who derived his views from Fraenkel and Benda-have been inclined to regard it invariably as congenital. In favor of this is the fact 
that 2 cases have been recorded occurring in newborn children, as well as the existence in several cases of distinct anomalies of the left lung and the presence in 2 cases of other forms of hernia. There is more difference of opinion as to how the lesion actually occurs. Thoma believes that the lung is chiefly at fault. He urges that weakness of the left side of the diaphragm cannot account for it, as in the foetus the liver protects both sides. There is a greater tendency on the part of the left lung to congenital malformation in the proportion, he finds, of 49 to 8 . He suggests that it is not impossible that eventration might occur on the right side, although hitherto no such case has been recorded. The arguments in favor of this view may be summarized as follows: First, the occurrence of congenital anomalies in the lung; second, the presence of muscular fibres in the diaphragm in several cases examined microscopically; third, the absence of anomalies in the great vessels arising from the heart. The mechanism is, of course, obvious. When the lung is too small the diaphragm rises to fill the space in the pleural cavity, dragging the intestinal contents with it.

The theory that the primary lesion is a congenital deficiency of the muscles of one side of the abdomen has been supported chiefly by Doering. In favor of his view he urges the marked deficiency in the muscular tissue of the affected side of the diaphragm, which has been found in all cases examined microscopically, and the symmetrical condition of the thorax. The mechanism is that the congenitally weak diaphragm fails to expand the lung, which remains atelectatic, and therefore the diaphragm assumes the high position, dragging the viscera with it. Against this view is, of course, the existence of anomalies in the lung; the fact that the lungs have never been found to be atelectatic; and, I believe, the invariable presence of dextrocardia. Glaser suggests as an explanation of his own case that there occurred a dystrophy of one-half of the muscle of the diaphragm, causing it to become weakened and to rise in the thorax as a result of the traction of the lung.

Tennant suggests that in his case there may have been a degenerative condition either of the left half of the diaphragm or of the terminals of the phrenic nerve. It does not appear that microscopic examination was made for the purpose of determining this important point. It is not an exaggeration of a normal condition, for Engel has proven that the diaphragm is normally higher on the right side.

There are, I think, certain points in this condition which require more careful consideration. The symmetrical thorax early attracted attention. Neisser believes that it is due merely to the greater compensation that can occur in the intrathoracic viscera in early childhood, and particularly to the absence of adhesions between 
the serous membranes. Doering implies that it is due to the tendency of the skeleton to develop symmetrically when there is no hindrance placed upon it. These views are practically identical. The fact that the diaphragm on the left side is thin and contains few muscular fibres is to my mind of considerable importance. If the primary lesion were merely a hypoplasia of the lung we should expect some evidence of hypertrophy of the muscular tissue as a result of the additional effort to which it was subjected. Such evidence is entirely lacking; indeed, in one case it was noted that even the pillars of the diaphragm were diminished in size. The dextrocardia hardly accords with the theory of primary hypoplasia of the lung. Assuming that the lung was too small, the natural effect of the tug of the diaphragm would be to displace the heart farther to the left. This is not merely a theoretical consideration. Cases have actually been reported in which, as a result of hypoplasia of the left lung, the heart was displaced to the left side. Reinhold has reported 3 cases: First, a woman aged twenty-four, with a symmetrical thorax and an apex in the left axillary line; there was tympany over the lower portion of the thorax; the autopsy showed bronchiectasis of the left lung and dislocation of the heart to the left. Second, a man of fifty-six years, with similar physical signs. Third, a man of thirty-two years, with an apex beat between the posterior axillary line and the angle of the scapula, and tympany over the lower portion of the left chest. Neisser has reported 4 cases: First, a man of forty-two years of age, with symmetrical, barrel-shaped thorax and an apex beat in the left midaxillary line at the level of the third rib; the diaphragm was high on the left side. Second, a boy of nine years, son of the preceding case, had almost identical physical signs. In 2 additional cases reported briefly there were similar physical signs, with the exception that in 1 there was deformity of the thorax. Heyse reports 1 case, a woman of forty-six years. There was no deformity of the thorax, but evidence of deficiency of the left lower lobe and the heart was dislocated far to the left. Sieveking reports a case with autopsy. The left lung was malformed and also showed evidence of an acquired lesion. The heart was displaced to the left.

These cases seem sufficient to establish the contention that there does exist a condition of hypoplasia of the left lung, with or without a high position of the diaphragm, and with dislocation of the heart to the left. In eventration it has generally been supposed that the dextrocardia is purely mechanical, due to the sliding of the heart down the hill produced by the ascent of the left half of the diaphragm, but such a dislocation could hardly occur as a result merely of hypoplasia of the lung, nor is there sufficient evidence in favor of Doering's view of simple weakness in the left half of the diaphragm. Therefore, it seems to me that we are compelled 
to assume that the two conditions coexist; in other words, that in the small number of cases of eventration of the diaphragm hitherto reported, with the possible exception of that of Glaser, there has been not merely a congenital hypoplasia of the lung, but also a hypoplasia or dystrophy of the left half of the diaphragm, and that the dislocation of the heart is due less to the movement upward of the diaphragm than to the elastic tension of the right lung. We confess that after reaching this conclusion the pathology of the whole condition is still entirely obscure. We do not know what is the nature of the atrophy of the diaphragm; whether it is due to some lesion of the nervous system, or of the muscle. The cause of the origin of congenital anomalies in the lungs is purely a matter of speculation.

Aside from the pathology of the subject there is but one other point that is of interest, and that is the diagnosis. This is certainly of importance, because in one of the recorded cases, as a result of a mistaken diagnosis of incarcerated diaphragmatic hernia, operation was performed, uselessly of course, but fortunately without disastrous results. The signs in the cases that have been studied clinically have been practically the same. In all there was normal percussion resonance in the upper portion of the left lung; tympany below a certain line, which varied from the second to the fourth ribs; tympany posteriorly, usually from the angle of the scapula down; the ordinary signs of displacement of the heart toward the right; the evidence of the presence of abdominal viscera in the lower portion of the left thorax-that is, gurgling and splashing, especially pronounced when the patient swallowed liquids; often an area of dulness in the lower part when the patient took a considerable amount of food, sometimes associated with distinct Hippocratic succussion. The coin test is negative. Frequently there is an area of dulness posteriorly which appears to be satisfactorily accounted for in 2 cases by the dislocation of the spleen. Litten's phenomenon is usually absent. The movement downward of the area of tympany on deep inspiration was present in 2 cases. The examination with the Roentgen ray in all cases showed that the abdominal viscera were in the lower portion of the left thorax, and this, in 1 certain case, was conclusively proven by introducing a stomach tube filled with mercury, which cast a shadow, and which could be seen coiled up in the position usually occupied by the left lung (Grosser's method). Clinical symptoms may be entirely absent. The gastric disturbances that occur may sometimes possibly be due to other causes; constipation is common enough not to ascribe it to the eventration; but in the case of Widenmann no cause for the hæmatemesis was found, excepting the dislocation of the stomach.

In making the differential diagnosis all those conditions must 
be excluded that produce tympany in the lower portion of the left chest. Among these probably the most important is pneumothorax. In Strüppler's case puncture was made nineteen times and in ours twice. On no occasion, fortunately, did the needle pierce the stomach wall. In left pneumothorax the respiratory movement is usually absent; the interspaces are dilated; the percussion note is resonant rather than tympanitic; the coin test is positive. In eventration of the diaphragm the respiratory movements are normal; the note in the lower part of the chest is clear and tympanitic, and, in the upper part, is resonant. There is loud gurgling - especially when the patient drinks water-heard over the lower part of the chest. The two conditions have in common dislocation of the heart to the right; Hippocratic succussion, which may disappear, however, in eventration of the diaphragm if the patient has fasted for a long time. If the stomach is inflated in pneumothorax there is distinct bulging in the left hypochondrium. In eventration this is not likely to occur, or is slight, and there is distinct bulging of the lower part of the thorax. Litten's phenomenon is apparently absent in both conditions. One of the most valuable differential signs is the fact that the upper border of tympany moves with respiration in eventration and does not move in pneumothorax. Examination with the Roentgen ray is decisive as regards the differential diagnosis between these two conditions. The presence of a sound filled with some opaque substance in the lower portion of the right thorax indicates that the stomach has risen in that region.

More difficulty would probably be experienced in the case of subdiaphragmatic pyopneumothorax. This is an exceedingly rare condition, and when it does occur is nearly always found upon the right side. The condition is very acute and the patients ordinarily are in a state of collapse, and as the commonest cause is the rupture of a gastric ulcer, a history pointing to the existence of this lesion can ordinarily be obtained. In the small number of published cases (von Leyden, Neusser) the symptoms have been tympany in the lower portion of the thorax, the upper border of which moves with respiration; the physical signs of movable fluid below this area of tympany; dislocation of the liver or of the spleen downward; a positive coin test, and slight, if any, dislocation of the heart. Presumably gurgling over the area of tympany was absent, because it is not inentioned in any of the cases.

The majority of cases of eventration of the diaphragm have been confounded clinically and pathologically with diaphragmatic hernia. According to Strüppler the diagnosis of this condition has been made correctly but nine times during life, not including those cases in which it was made as a result of an exploratory voL. 129, No, 4.-APRIL, 1905. 
incision. It is therefore fair to conclude, in view of the fact that more than 500 cases have been recorded, that it is exceedingly difficult. It is interesting to note that 1 of the 9 cases was that of Widenmann, which was subsequently shown to be one of eventration of the diaphragm.

The majority of analyses of the symptoms that have been published are based upon the study of single cases, and therefore are only of suggestive value. Diaphragmatic hernia usually occurs upon the left side, giving rise to an area of tympany in the lower portion of the thorax, causing displacement of the heart to the right and compression of the left lung. There is gurgling over the tympanitic area, and the physical signs, therefore, must be practically identical with those of eventration of the diaphragm, with the possible exception that the upper border of tympany does not move with respiration. Unfortunately in none of the published cases of diaphragmatic hernia, as well as we have been able to ascertain, has attention been paid to this point. In traumatic cases of diaphragmatic hernia the history of severe injury will be of great assistance. Extraordinary variability in the symptoms is common to both conditions, and the case of Glaser shows that signs of incarceration may occur in cases of eventration. Dysphagia paradoxica has not yet been reported in this condition, and is by no means common in diaphragmatic hernia. There was a history of persistent thirst in our case, and this has been noted in several cases of diaphragmatic hernia. Examination with the $x$-ray has been shown to be inconclusive, although apparently respiratory movement of the convex line bounding the clear area is in favor of eventration of the diaphragm.

Acquired high position of the diaphragm may apparently occur. Glaser inflated two dilated stomachs ad naximum and found that the diaphragm moved upward a full interspace on the left side. It does not appear that idiopathic dilatation of the stomach produces this displacement. Very little is known of the results of disease of the phrenic nerve. Stockton, however, has reported an extraordinary case which he records as phrenic paralysis, in which there was high position of the diaphragm and tympany in the lower portion of the left thorax. It is not stated whether or not the area of tympany moved up and down during respiration or not, but presumably it did not do so. The symptoms that are described strongly suggest eventration of the diaphragm, but the patient made a complete recovery with disappearance of all the physical signs, indicating that the lesion was transient and not congenital. Without a very clear history it would seem practically impossible to differentiate the two conditions. Cavity or dilated bronchus in the left lung could hardly give rise to difficulty in diagnosis. The character of expectoration, 
the absence of displacement of the heart, the amphoric respiration, bronchophony, and pectoriloquy would serve almost immediately to make the diagnosis clear.

\title{
LTTERATURE.
}

\author{
Abercrombie. Edinburgh Medical Transactions. Quoted by Clark. \\ Bowditch. Boston Medical and Surglcal Journal, 1853-54, vol. Ix. p. 65. \\ Barlow. British Med. Jour., Jenuary 3, 1880. \\ Clark, C. J. THE AMreicas Journal of The Medical Sciences, 1850, p. 106. \\ Crispino. Riforma Medica, 1900, Nos. 187 to 189. \\ Cruveilhier. Traité de l'anat. path. genérale, Paris, 1849, vol. i. p. 617. \\ Doering. Deutsche Archiv f. klin. Med., 1902, vol. 1xxii. p. 407. \\ Engel. Wiener kiln, Woch., 1868, p. 121. \\ Froriep. Kleinert's Repertorium, 1837. \\ Freenkel. Centralbl, f, innere Med, 1892, p. 1201 ; 1893, p. 27. \\ Fitzgerald and Everett. British Med. Jour., September 18, 1900. \\ Grosser. Wiener klin. Woch., 1899, p. 655. \\ Glaser. Deutsche Archly f. klin. Med., 1903, vol. 1xxvili. p. 370. \\ Hirsch. Münchener med. Woch., 1900, p. 996. \\ Heyse. Deut. med. Woch. 1903, No. 44. \\ Kronig. Centralbl. f. Innere Med., 1898, vol. xlx. p. 178. \\ Kaufmann. Deut. med. Woch., 1887, No. 28. \\ Laacher. Deutsche Archiv f. klln. Med., 1880, vol. xxvll. p. 268. \\ Leichtenstein. Zlemsen's Eandbuch der Speciellen Path. und Therap., 1876, vol. vil., part \\ 11. p. 439 . \\ Lawrence. Lancet, 1852, vol. 11. p. 827. \\ Marsh. Lancet, 1867, vol. 1. p. 298. \\ Meckel. Quoted by Laacher. \\ Nelsser. Zeitschrif f. klin. Med., vol. xlil. p. 88. \\ Neusser. Wiener med. Woch., 1884, p. 1806. \\ Petit. Traité de maladies chirurg., 1790, vol. 11. p. 234. \\ Pyl. Quoted by Laacher. \\ Reinhold. Münchener med. Woch., 1893, p. 845. \\ Struppler. Deutsche Archiv f. klin. Med., 1901, vol. vil. p. 1. \\ Stockton. Buffalo Medical Journa), 1898-99, p. 97. \\ Slevelking. Münchener med. Woch., 1895, p. 68. \\ Tennant. Edinburgh Medica! Jour., July, 1894, p. 29. \\ Thoma. Virchow's Archlv, 1882, vol. Ixxxvili. p. 515. \\ Widenmann. Berllner klin. Woch., 1901, No. 11.
}

